\title{
Characterisation of Bituminous Mix Using River Bed Materials
}

\author{
Manoj K. Sahis ${ }^{1}$, Dipesh Majumdar ${ }^{2}$, Partha P.Biswas ${ }^{3}$, Sourav Halder ${ }^{4}$, Agnimitra Sengupta ${ }^{5}$ \\ Department of Construction Engineering \\ Jadavpur University, Kolkata, India \\ ${ }^{1}$ manojsahis@gmail.com, ${ }^{2}$ dipeshce@gmail.com, ${ }^{3} \mathrm{drppb} @$ yahoo.in, \\ ${ }^{4}$ souravhaldar@gmail.com, ${ }^{5}$ senguptaagni@gmail.com
}

Abstract-Construction of highway involves enormous outlay of investment. A precise engineering design save considerable investment as well as a reliable performance of the in-service highway can be achieved. Two things that are of major considerations in flexible pavement engineering are pavement design and the mix design. A good design of bituminous mix is expected to satisfy strength, durability and economic criteria. The present study is related to the mix design using River Bed Material sample from two sources. Characterization of different mixes namely; Dense Bituminous Macadam, Bituminous Macadam and Semi Dense Bituminous Concrete have been done using river bed materials from varied sources. Suitability and optimum bitumen content has been verified in terms of stability value, flow value etc. for each type of mix for use in pavement construction.

Keyword - mastic asphalt, marshal mix design, river bed material, optimum bitumen content

\section{INTRODUCTION}

Optimization of project costs and quality in construction is one of the major targets in industry. In case of a road project, the issues that are of utmost importance are the design of pavement and the mix design. For a bituminous mix to be selected, it is essential to be satisfactory in terms of strength, durability and economic parameters. Hence continuous search for alternative materials to be used in construction gained impetus.

The River Bed Materials (RBM) are an accumulation or deposit of material derived naturally from the disintegration of rocks. Different rivers having various types of bed materials take a major role in civil construction projects in the adjoining area.

The major sources of coarse aggregate in West Bengal are both situated in Jharkhand, so huge transportation cost of coarse aggregates make the road construction project uneconomic.

In recent times, RBM have been gaining popularity in the field of construction due to its high availability and also taking major role in road projects including rural road. The application of RBM in flexible pavement construction, particularly as granular base and sub base, is gaining momentum in PMGSY road network due to optimization of project cost. Moreover collection, transportation and segregation of RBM can also be considered as a potential source of employment of local people, and thus having a positive socio-economic impact.

The present investigation characterizes and determines the suitability of various RBM modified bituminous mixes- Dense Bituminous Macadam, Bituminous Macadam and Semi Dense Bituminous Concrete, to be used in pavement construction.

\section{LITERATURE REVIEW}

Various research works has already been done on the different aspects on bituminous macadam in different countries. Attempts to determine optimum bitumen content for DBM by Marshall Mix Design which corresponds to maximum stability and adequate workability as per Indian road condition have been undertaken. Laboratory compacted trial specimen were used for volumetric and mechanical testing in order to predict flow and stability of the mix as per MORTH specification [1].

Alternative to standard materials like locally available soil-gravel mix, kankar etc. were used in mixes for rural road. This locally available material was utilized to the maximum extent for the construction of various layers of the sections. Some of the sections were without bitumen surfacing while others had surfacing with low graded material like kankar. The performance study showed that the portion of pavement with a granular base with thickness ranging 10 to $15 \mathrm{~cm}$ with premix carpet was found most durable up to five years [2].

Aggarwal Praveen [3] investigated the suitability of Wet Mix Macadam (WMM) construction cost and compared with respect to crushed sand and stone dust of five types of locally available materials. Simulation of test results were found suitable in terms of MORTH requirements in use of WMM construction and found a saving of cost of $6 \%$ to $13 \%$ by using such materials.

Effects of shape of aggregates on bitumen pavement were studied where different shapes were chosen for sample preparation for Marshall Mix. The study revealed superior results in cases of cubical shape of aggregates 
in terms of optimum bitumen content and stability although all types of aggregate are satisfied the MORTH specification, but mix with cubical aggregate give closer value to the mid limit of flow value [4]

Jain P.K et al (2014) [5] focused on improvement in water absorption and impact value of three low quality aggregate like brick bats, sand stone and shale. These materials were treated with different process like coating with 80/100 penetration grade bitumen, soaking of aggregates in bitumen kerosene oil bend, soaking in urea formaldehyde resin and soaking in sodium silicate solution. Studies show that after treatment, different types of low quality aggregates improved their water-absorption and wet strength characteristics and suitable for use in different course of rural roads.

According to the findings of Kandhal P.S et al [6], recommendations for designing long lasting bituminous road in India includes the use of viscosity grade instead of penetration grade as per climatic condition of India and is also focused on no need to restrict the use of natural sand (which tends to have rounded particles) upto10 per cent in wearing and binder course (within top $100 \mathrm{~mm}$ of pavement) and to 50 per cent in base course (more than $100 \mathrm{~mm}$ from the pavement surface).

Asphalt Institute MS-2 [7] should be followed completely in designing dense graded bituminous mixes using the Marshall method. This includes selecting design bitumen content corresponding to 4.0 per cent air voids. Maximum specific gravity of mix should not be calculated with a formula but measured by using ASTM D $2041[8]$.

The MORTH Specifications [9] do not have adequate mat compaction requirements. It has been recommended that the density of the finished compacted layer should not be less than 92 per cent or more than 97 per cent of the theoretical maximum specific gravity of loose mix determined by ASTM D 2041. $150 \mathrm{~mm}$ diameter cores should be obtained to measure the pavement density.

\section{III.MATERIAL CHARACTERISATION}

Material characteristics of each and every component have its influence on the properties of the mix, both in terms of strength and durability. For this reason, materials used in the present study have been characterized using Indian Standard Specifications as far as possible.

Bitumen: In paving, bitumen acts as a binder of the aggregate that ensures the structural strength and texture of the road surface. Properties of the binder are depicted in Table I.

TABLE I: Physical properties of bitumen

\begin{tabular}{llll}
\hline Sl. No & Description & Test Method & Test Results \\
\hline 1 & Specific gravity & IS 1202-1978 & 1.03 \\
2 & Flash Point & IS 1209-1978 & 229 Degree C \\
3 & Soluble in Trichloroethylene & IS $1216-1978^{\mathbf{1 2}}$ & $99.61 \%$ \\
4 & Penetration value & IS 1203-1978 & $35 \mathrm{~mm}$ \\
5 & Softening point & IS $1205-1978^{\mathbf{1 4}}$ & 52 degree c \\
6 & Elongation & IS 1208-1978 & $930 \mathrm{~mm}$ \\
7 & Viscosity & IS 1206-1978 & VG 40 \\
\hline
\end{tabular}

River Bed Aggregates: Aggregates from different sources have been chosen for analysis of bituminous mixes, as shown in Table II. Table III specifies the physical properties of the aggregates tested in accordance to IS 2386-1997 [17].

TABLE II: Sources of River Bed Materials

\begin{tabular}{lll}
\hline Sl. No & Name of the River & Designation of Sample \\
\hline 1 & Teesta River & T \\
2 & Balason River & B \\
\hline
\end{tabular}


TABLE III: Physical Properties of RBM from both sources

\begin{tabular}{lll}
\hline Sample & T & B \\
\hline Specific. Gravity & 2.7 & 2.68 \\
Water Absorption & $0.60 \%$ & $0.65 \%$ \\
Flakiness Index & $38 \%$ & $26 \%$ \\
Elongation & $21 \%$ & $18 \%$ \\
Aggregate Impact value & $15 \%$ & $17 \%$ \\
Los-Angeles Abrasion Test & $34.7 \%$ & $40.5 \%$ \\
\hline
\end{tabular}

\section{IV.EXPERimental Program}

The present work involves study of suitability of river bed materials (RBM) extracted from the sources mentioned in Table II, to be used in different bituminous mixes namely, Dense Bituminous Macadam (DBM), Bituminous Macadam (BM) and Semi Dense Bituminous Concrete (SDBC).

Test samples have been prepared with varying bitumen contents (3\% to $7 \%$ ) with the objective of evaluating the optimum bitumen content for mixes prepared with coarse aggregate and fine aggregate sample obtain from river bed material, by performing the following tests:

1. Marshall Stability Test

2. Flow Value Test

3. Density- Void Ratio Tests

TABLE IV: Requirement for bituminous mixes as per MORTH specifications

\begin{tabular}{lllll}
\hline Sl. no & Parameter & DBM & BM & SDBC \\
\hline 1 & $\begin{array}{l}\text { Bitumen \% by weight of } \\
\text { the aggregate }\end{array}$ & $4.0 \%$ (minimum) & 3.1 (minimum) & 4.5 (minimum) \\
2 & $\begin{array}{l}\text { No of blow on each side } \\
\text { of specimen }\end{array}$ & 75 & 75 & 75 \\
& Stability $(\mathrm{KN})$ & 9 (minimum) & 9 (minimum) & 8.2 (minimum) \\
3. & Flow $(\mathrm{mm})$ & $2-4$ & $2-4$ & $2-4$ \\
4. & $\mathrm{~V}_{\mathrm{a}}(\%)$ & $3-6$ & $3-6$ & $3-5$ \\
5. & $\mathrm{~V}_{\text {ma }}(\%)$ & Table $500-12$ & Table $500-12$ & Table $500-12$ \\
6. & $\mathrm{~V}_{\mathrm{fb}}(\%)$ & $65-75$ & $65-75$ & $65-78$ \\
7. & Density $(\mathrm{g} / \mathrm{cc})$ & - & - & - \\
\hline 8. & & & & \\
\hline
\end{tabular}

\section{Results\& Discussions}

To obtain the optimum bitumen content for the selected grading of aggregate and for each type of mix, test specimens were prepared with binder content varying from $3.0 \%$ to $7.0 \%$ with an interval of $0.5 \%$. Three specimens each corresponding to specific binder content was prepared.

The graded aggregate were heated to a temperature of $150^{\circ} \mathrm{C}$ and the required proportion of bitumen by weight of the aggregate are also heated to a temperature of $150^{\circ}-160^{\circ} \mathrm{C}$. The heated aggregate and bitumen were mixed at a temperature of $160^{\circ} \mathrm{C}$. The test specimen were prepared and tested under following relevant guideline described in MORTH specification.

The test results have been presented in the following section for each of the three types of bituminous mixes with RBM aggregate sample from source $\mathrm{T}$ and $\mathrm{B}$ respectively. 


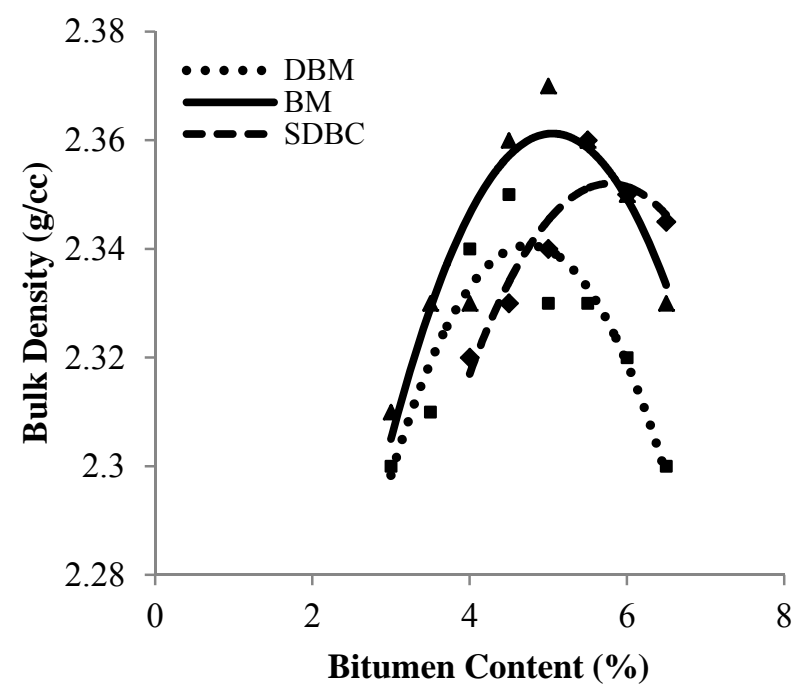

Fig 1a: Variation of Bulk Density with Bitumen Conten DBM, BM and SDBC using RBM sample from source T

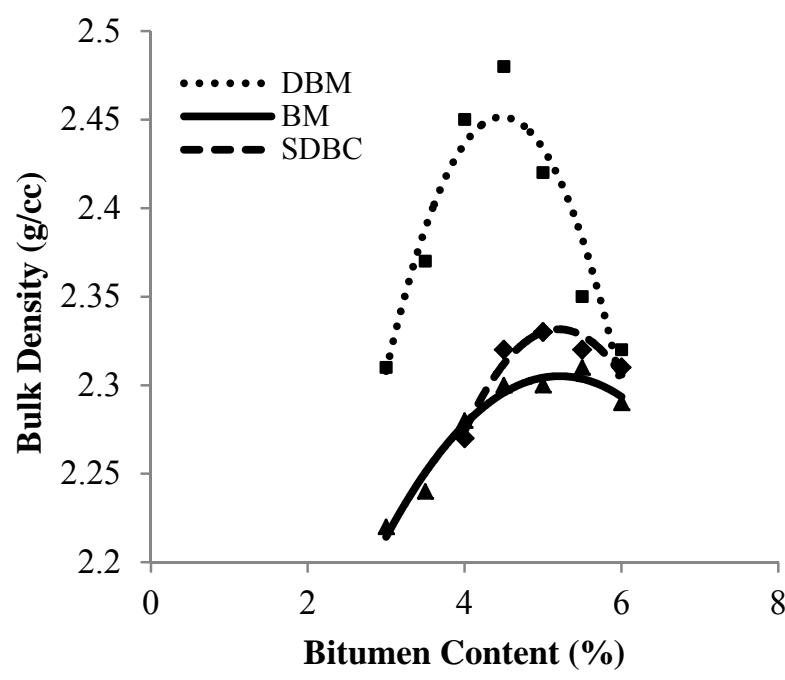

Fig 2a: Variation of $\mathrm{V}_{\mathrm{ma}}$ with Bitumen Content for DBM, $\mathrm{BM}$ and SDBC using RBM sample from source $\mathrm{T}$

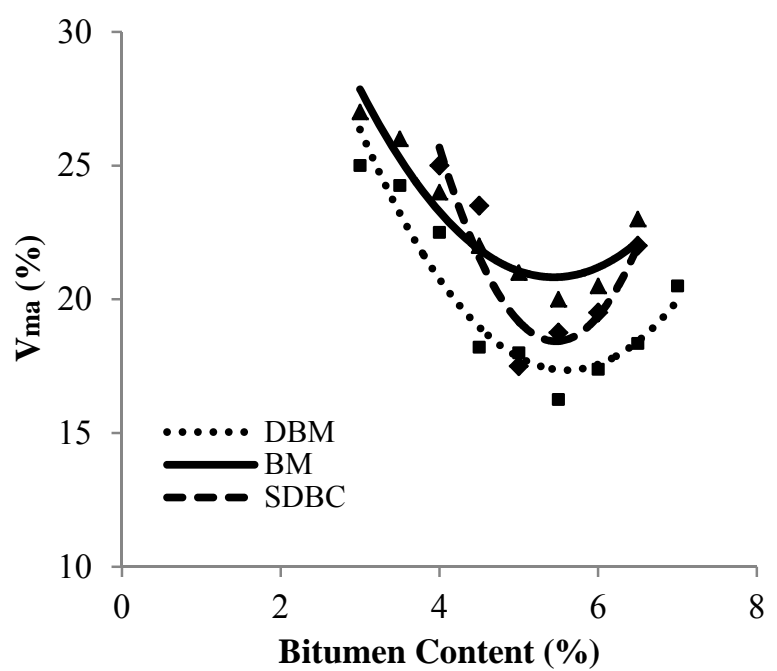

Fig 3a: Variation of $\mathrm{V}_{\mathrm{fb}}$ with Bitumen Content for DBM, $\mathrm{BM}$ and SDBC using RBM samplefrom source $\mathrm{T}$

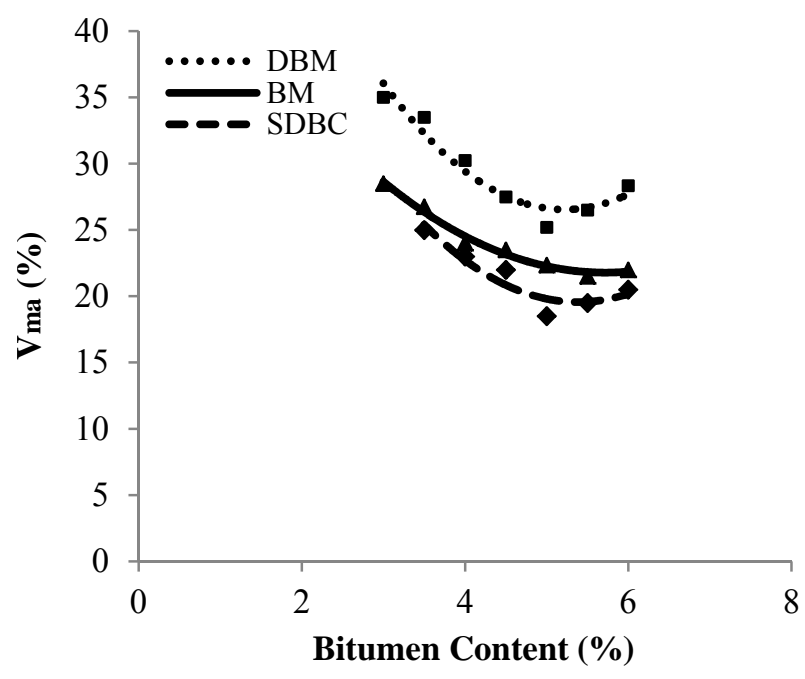

Fig 1b: Variation of Bulk Density with Bitumen Content DBM, BM and SDBC using RBM sample from source B

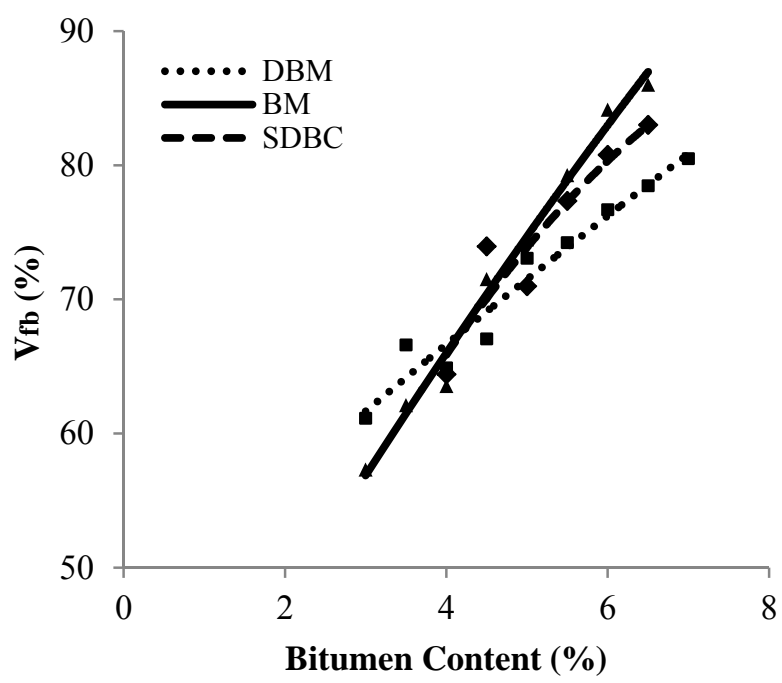

Fig 2b: Variation of $\mathrm{V}_{\mathrm{ma}}$ with Bitumen Content for DBM, $\mathrm{BM}$ and SDBC using RBM sample from source B

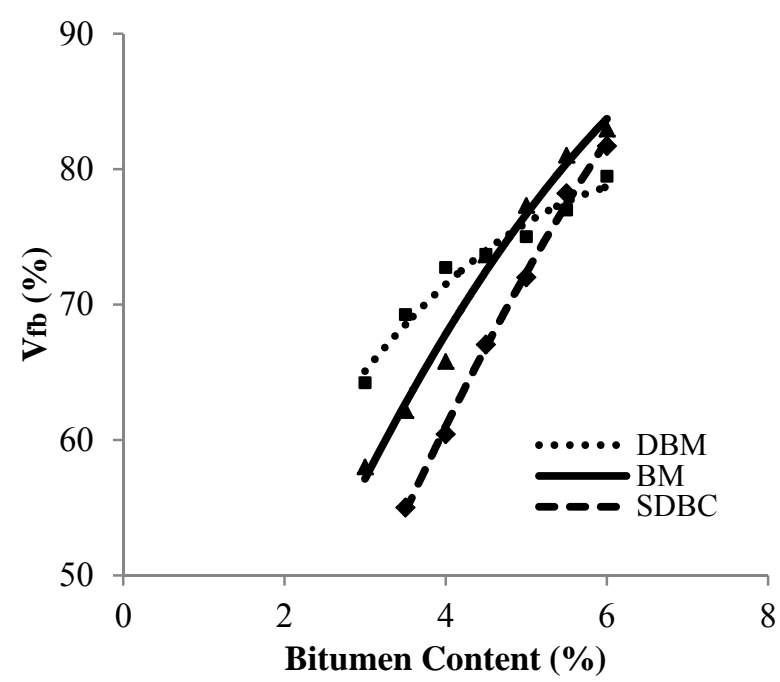

Fig 3b: Variation of $\mathrm{V}_{\mathrm{fb}}$ with Bitumen Content for DBM, $\mathrm{BM}$ and $\mathrm{SDBC}$ using RBM sample from source $\mathrm{B}$ 


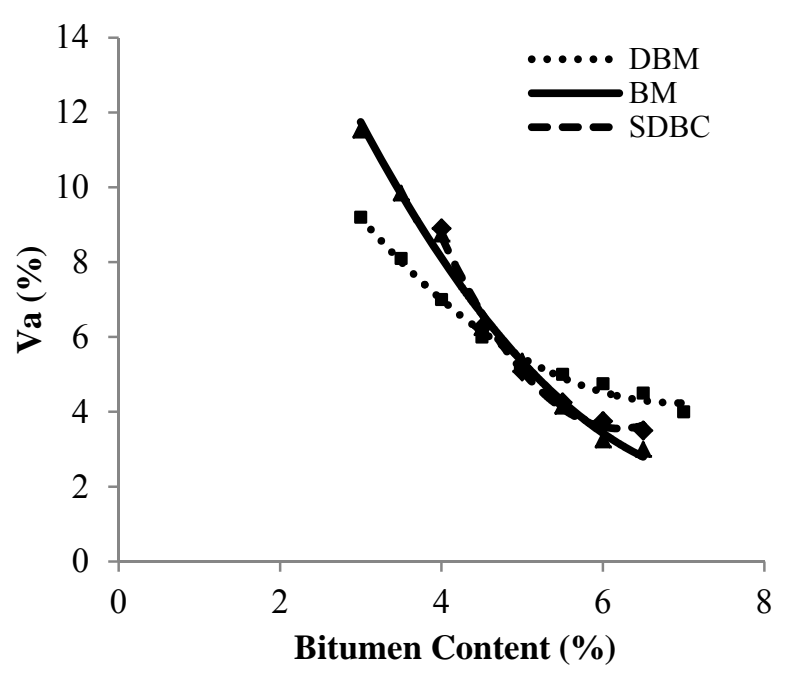

Fig 4a: Variation of $\mathrm{V}_{\mathrm{a}}$ with Bitumen Content for DBM, $\mathrm{BM}$ and SDBC using RBM sample from source $\mathrm{T}$

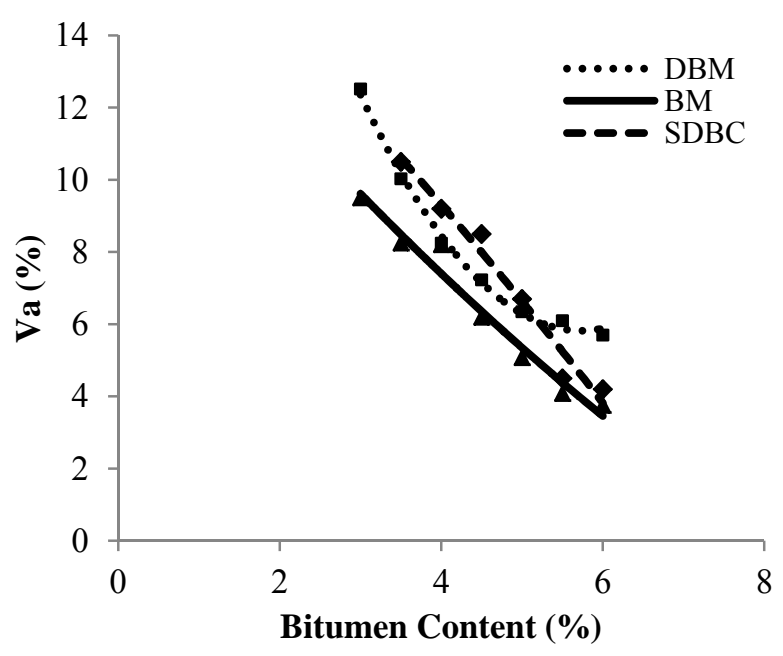

Fig 5a: Variation of Stability with Bitumen Content for DBM, BM and SDBC using RBM sample from source T

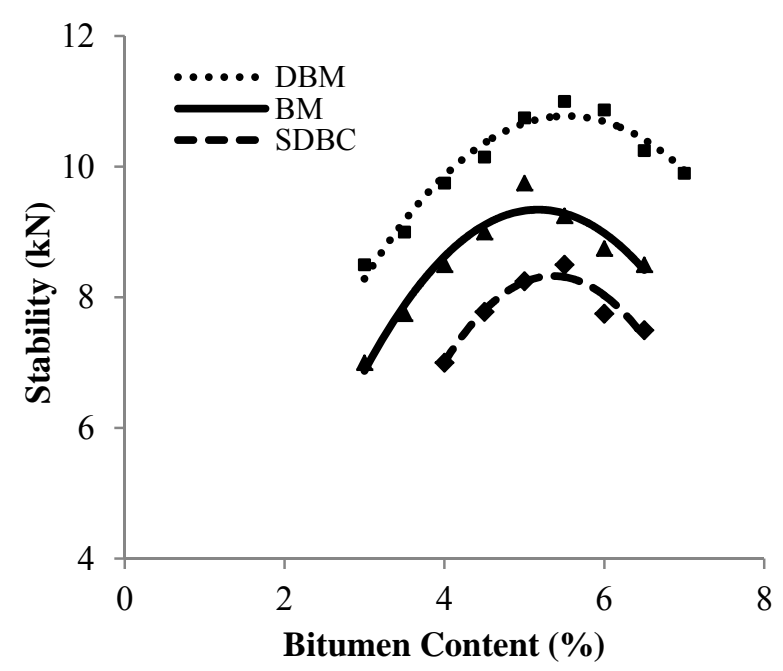

Fig 6a: Variation of Flow Value with Bitumen Content for DBM, BM and SDBC using RBM sample from source $\mathrm{T}$

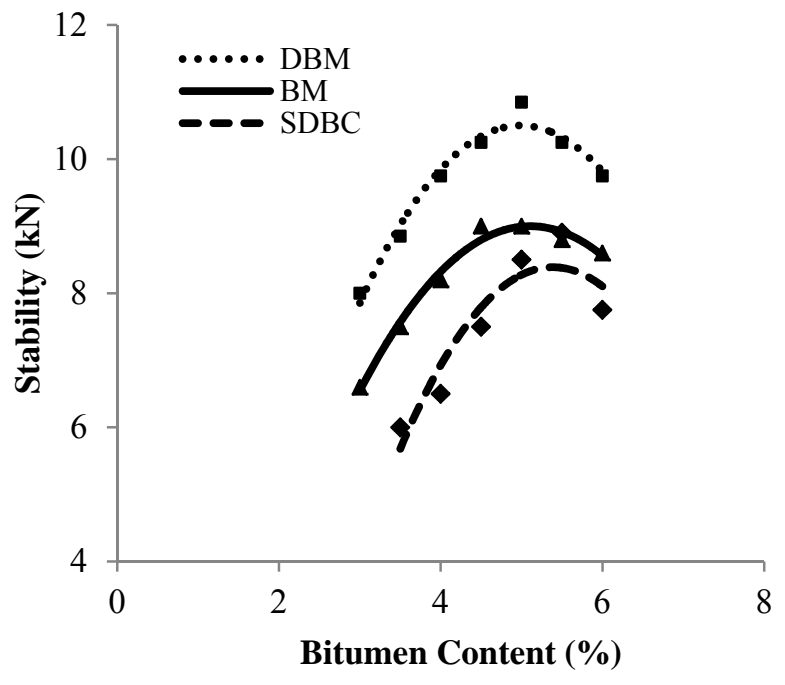

Fig 4b: Variation of $\mathrm{V}_{\mathrm{a}}$ with Bitumen Content for DBM, $\mathrm{BM}$ and SDBC using RBM sample from source $B$

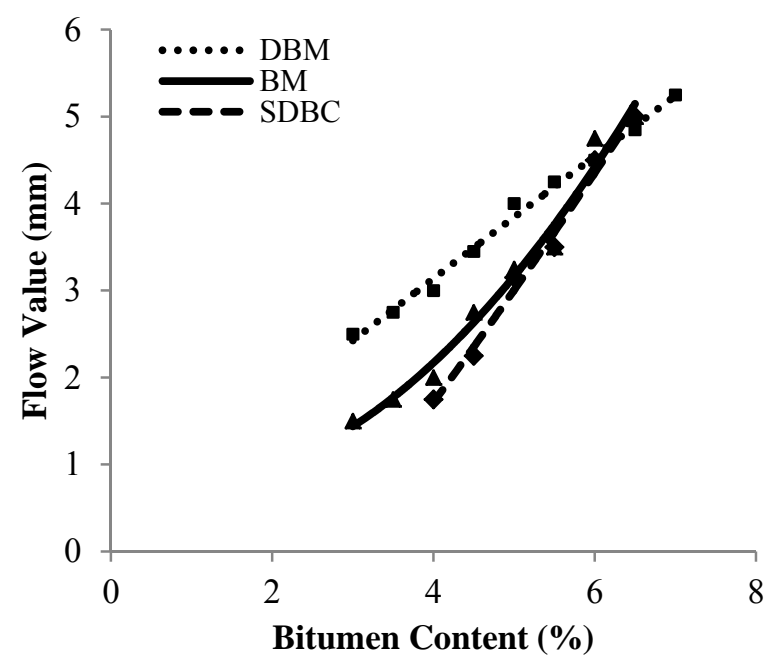

Fig 5b: Variation of Stability with Bitumen Content for DBM, BM and SDBC using RBM sample from source B

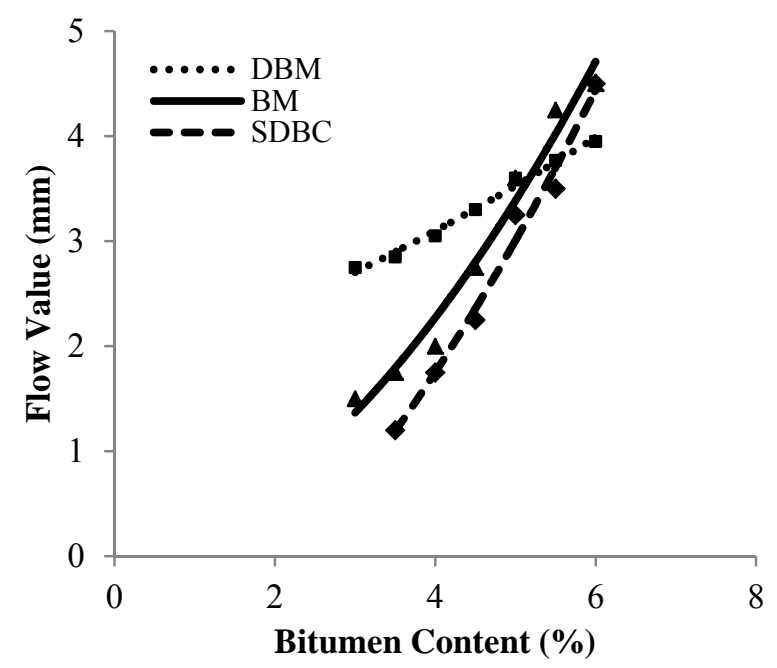

Fig 6a: Variation of Flow Value with Bitumen Content for DBM, BM and SDBC using RBM sample from source B 
Fig $1 \mathrm{a}$ and $1 \mathrm{~b}$ depict the nature of variation of the bulk density with respect to bituminous content in the mix for samples from both sources $\mathrm{T}$ and $\mathrm{B}$. As evident from the figures, each mix reaches a point of maximum density corresponding to a definite bitumen content which complies with the specifications of Table IV.

The effect of increase in bitumen content on $V_{m a}$ has been presented in Fig $2 a$ and $2 b$ for RBM sample from sources $\mathrm{T}$ and $\mathrm{B}$ respectively. Each of the curves shares a common trend of variation which indicates a minimum void in mineral aggregates for optimum bitumen content. Each of the results satisfied Table 500-12 of MORTH specifications.

Referring Fig $3 \mathrm{a}$ and $3 \mathrm{~b}, \mathrm{~V}_{\mathrm{fb}}$ is found to increase at a decreasing rate with the increase in the percentage of bitumen in the mix. In case of BM and SDBC using RBM from source B, values of $\mathrm{V}_{\mathrm{fb}}$ are $81 \%$ and $64 \%$ respectively, both of which lie outside the permissible range (65-78\%). Hence RBM from source B is not suitable for use in BM and SDBC.

Increase in binder content reduces the percentage of air void in the mix as evident from Fig $4 \mathrm{a}$ and $4 \mathrm{~b}$. SDBC mix using RBM from source B resulted in a air void percentage value of $6.75 \%$ that exceeds the permissible value of $3 \%$ to $5 \%$ as per MORTH. Hence RBM from source B is unsuitable for use in SDBC.

Fig $5 \mathrm{a}$ and $5 \mathrm{~b}$ represent the nature of variation of stability versus the bitumen content in the mix proportions for both sources. For definite bitumen content, each type of mix attains a maximum stability value which contributes to judge the optimum bitumen content. As per this study, stability values for BM and SDBC with aggregates from source B are $8.9 \mathrm{kN}$ and $8.15 \mathrm{kN}$ respectively, which are less than the minimum criteria stated in Table IV.

General trend of variation of the flow value with increase in binder content has been presented in Figures 6a and $6 \mathrm{~b}$ for mix using RBM from source $\mathrm{T}$ and $\mathrm{B}$ respectively. It has been observed that flow value in case of BM using source B aggregates is $4.25 \mathrm{~mm}$ that exceeds the permissible maximum value of $4.0 \mathrm{~mm}$.

\section{VI.CONCLUSION}

As evident from the test statistics, on comparison with the MORTH specifications that RBM samples from source $\mathrm{T}$ can be recommended to be used for the three types of mixes, DBM, BM and SDBC, whereas samples from source B can be used for DBM only since it failed to comply to specifications in case for BM and SD.

\section{REFERENCES}

[1] Darshana.B Joshi et al (2009) "Optimum Bitumen Content by Marshall Mix Design for DBM" Journal of information knowledge and research in Civil Engineering, Volume 2, issue 2, May 2009.

[2] Bhasin N.K et al (1987)."A study on use of Low Grade Materials for Road construction in Rural Areas" Indian Highways, Vol.31 May 1987.

[3] Aggarwal Praveen (2013) "Application of Locally Available sand in Wet mix macadam Construction" Indian Highways, Vol.31 August 2013.

[4] Mansuri M.N (2014)"To study the influence of shape of coarse aggregate on DBM mix" Journal of international academic research for multidisciplinary, ISSN 2320-5083, Vol 2, June 2014.

[5] Jain P.K et al (2014) "Strength and durability characteristics of high-strength concrete with recycled aggregate-influence of processing" Journal of Sustainable Cement-Based Materials, ISSN 2165-0381, Vol 4, 2014.

[6] Kandhal P.S (2010)"Guideline for long lasting Bituminous pavements in India" Vol.35, Indian Highways, Paper no 564,December 2010.

[7] MS-2 Asphalt Mix Design Methods, ISBN: 9781934154700, 2015.

[8] American Society for Testing and materials (ASTM) D 2041-95 Maximum Theoretical Density of asphalt Apparatus.

[9] Ministry of Road Transport \& Highway specification for Road \& Bridge work, Sec500, $4^{\text {th }}$ Edition, 2001 Indian Road Congress, New Delhi.

[10] Bureau of Indian Standards IS 1202-1978, Methods For Testing Tar And Bituminous Materials: Determination Of Specific Gravity.

[11] Bureau of Indian Standards IS 1209-1978, Methods For Testing Tar And Bituminous Materials: Determination Of Flash Point And Fire Point.

[12] Bureau of Indian Standards IS 1216-1978, Methods For Testing Tar And Bituminous Materials: Determination Of solubility in carbon Di-sulphide Trichloroethylene.

[13] Bureau of Indian Standards IS 1203-1978, Methods For Testing Tar And Bituminous Materials: Determination Of Penetration Value.

[14] Bureau of Indian Standards IS 1205-1978, Methods For Testing Tar And Bituminous Materials: Determination Of Softening Point.

[15] Bureau of Indian Standards IS 1208-1978, Methods For Testing Tar And Bituminous Materials: Determination Of Ductility.

[16] Bureau of Indian Standards IS 1206-1978, Method For Testing Tar And Bituminous Materials: Determination Of Viscosity.

[17] Bureau of Indian Standards IS 2386-1997, Methods Of Test For Aggregate For Concrete. 